\section{THE EFFECTS OF UNILATERAL CASTRATION UPON THE PROSTATE.}

BY E. HURRY FEN WICK, F.R.C.S.,

Surgeon to the London Hospital, and to St. Peter's Hospital for Stone and Urinary Disease.

I note in the British Medical Journal of March 2nd, p. 508, that Dr. White, of Philadelphia, is desirous of obtaining information as to the effects of unilateral castration upon the total bulk of the prostate. He surmises, also, that one-sided atrophy of the prostate commonly results upon the removal of the corresponding testis, and that the same condition is met with in monorchids. Logically, the same result should ensue upon the absolute atrophy of one testis from any cause.

As I have been investigating the physiological relation between the testes and the prostate for ten years, and have taken as my guide the contour and consistency of the pro. state as estimated by rectal examination, I am able to offer Dr. White a few facts upon the subject.

I have excerpted from my noteoooks some twenty cases which may be grouped, according to the issues which have been raised, under the heads of unilat ral castration, monorchids, and atrophic testes of minute size (small bean to pea size). These cases are taken consecutively, and are not selected. They are now described as they were noted at the time, each was accompanied by a diagram, and I think that they may be taken as fairly accurate, as I have specially educated my finger to detect changes in the contour of the prostate. Since 1886 I have been in the habit of making clay models or drawings of each prostate which I have examined, and my material in this respect has been abundant.

I seize this opportunity of endorsing Dr. White's statement concerning the shrinkage of the prostate after bilateral castration, and of expressing my belief that the profession and our patients owe him a real debt of gratitude for the introduction of an important addition to our means of combating certain forms of the enlarged senile prostate.

$$
\text { Unilateral Castration. }
$$

1. Left testis removed for tuberculusis 1889 ; prostate examined 1890 left lobe equal to right, both healthy, neither atrophic.

2. Left testis removed 1863 ; examined 1889 ; left lobe of prostate larger than right.

3. Left testis ablated 1887 ; examined 1894 ; very little prostate felt, and what was detected of it was coufused; no interlobular furrow appreciable.

MONORCHIDS

4. Left testis absent; left lobe of prostate flat, slightly larger than right.

5. Left testis absent; left lobe of prostate atrophied, right lobe normal. Extre Me ATrophy of Testis. A. After inflammation.

6. Left testis minute; both lobes of prostate equal, but flattened.

7. Left testis minute; left lobe of prostate large, right lobe atrophic

7. Left testis minute; left lobe of prostate large, right lobe atrophic. small.

9. Left testis very small; left lobe of prostate larger than right.

9. Left testis very small; left lobe of prostate larger than right. 10. Right

11. Left testis minute; both lobes of prostate equal, smooth, and plump.

B. Cause of atrophy unknown.

12. Left testis very small $;$ both lobes of prostate equal

13. Kight testis atrophic; lobes of prostate equal, flattened, and cupped.

14 Left testis small; prostate of average size, left lobe slightly the larger.

15. Left testis unfeelable ; prostate equal lobed.

16. Left testis small; left lobe of prostate the smaller.

17. Left testis small; prostatic lobes of equal size. but flattened.

18. Both testes retained in groin, and very small; both lobes of prostate equal; became aftected by infiltrating carcinoma (primary)

equal ; became aftected by infiltrating carcinoma (priniary). small.

20. This case is interesting : left testis in groin very small ; patient sud denly affected with gonorrhoal parenchymatous prostatitis; both lobes denly affected with gonorrhoal parenchy

I point out with some diffidence that these cases are mostly at variance with Dr. White's surmises. At the same time $\mathrm{I}$ am aware that rectal examination, however skilled, is as uncertain a guide to the activity of the prostate, as it is unreliable for estimating the amount of urinary obstruction which may be present. Moreover, none of us know the normal shape of the prostate, for it varies with each decade and with each individual. Lastly, few seem to appreciate the fact that the prostate is often changed in rectal contour by posture, by vesical distention, and by excessive use.
OBSTRUCTION OF THE BOWELS CAUSED BY GALL STONE : LAPAROTOMY : ENTEROTOMY.

\author{
By F. W. E. KINNEIR, M.R.C.S., L.S.A., \\ Horsham.
}

Mrs. B., aged 57, was taken with sudden abdominal pain followed by sickness on January 14th. On the following morning she passed two loose motions. The sickness continued, and stercoraceous vomiting commenced on January 17th. I was called in to see the patient on January 20 th by the family medical attendant, and performed laparotomy on January 21st. I found a large gall stone impacted in the upper part of the ileum, which I removed by enterotomy. After the operation the sickness ceased for some hours, the patient was conscious and expressed relief, and took some nourishment. About six hours later she vomited, but not fæcal matter. This continued at intervals during January 22nd, and on the morning of January 23rd the vomit became again stercoraceous and very offensive. She died on the afternoon of that day. There was no swelling of the abdomen before or after the operation and very little pain; the temperature was normal throughout. Very little urine was passed, and constipation was complete from January 15th in spite of medical treatment. She passed flatus frequently before she died. After the operation she was fed on soda water, some brandy, and nutrient suppositories. Morphine was injected hypodermically.

The operation was performed without any difficulty, the patient taking the anæsthetic well, chloroform and ether mixed being used. The abdomen was opened by a median incision, the small intestine was exposed distended with flatus ; this was followed down for some distance till the obstruction was found firmly impacted in the gut, which was collapsed below. As it could not be moved and the intestine looked inflamed and of a dark red colour, I decided to perform enterotomy, and the obstruction shelled out easily. I closed the wound by continuous catgut suture. The peritoneum was brought together and united with chromic gut, and the abdominal wound with deep and superficial silver sutures. The gall stone was covered with a layer of hard fæcal matter; it measured $1 \frac{1}{4}$ inch in diameter, its weight was $2 \frac{3}{4}$ drachms, and it resembled a walnut. On section it presented the usual yellow striated centre, getting darker towards the circumference.

Post-mortem Examination.-The median incision had begun to unite; there was no trace of peritonitis, and no serum or fluid in the cavity. The wound in the intestine was quite unchanged; the small intestine nearly down to the cæecum was distended. There was no other sign of obstruction from the duodenum to the anus. The mesentery at the seat of the obstruction and the intestine itself was of a dark gree colour.

REMARKS.- I am encouraged to publish this case on account of the interesting discussion on the subject, which took place at a meeting of the Royal Medical and Chirurgical Society, held on January 22 nd, and because, as it seems, intestinal obstruction produced by gall stone is rare. This patient had a sharp attack of colic and vomiting seven years ago, and gall stone was thought to be the cause. Since then she hifs complained of slight attacks. After seeing the case I decided to operate as quickly as possible, and on any future occasion I should feel encouraged to operate soon, as I feel sure in an earlier stage the operation would meet with a better chance of success. In this instance the fatal issue was evidently brought about by gangrene and paralysis of the bowel, on account of the continued pressure.

ON the occasion of the presentation of the certificates to the successful members of the Great Western Railway ambulance class at Banbury, a testimonial was presented by the class to its instructor, Surgeon. Captain Raye.

Presentatron.-Dr. T. C. Leman, of Chipping Sodbury, has been presented by the members of the Ladies St. John Ambulance Class of that town with a silver cigarette case and matchbox in appreciation of his services as lecturer to the c'ass. 